\title{
Forensic Medicine Practice in the Time of COVID-19 Pandemic: Challenges and Future Perspectives Shereen A Elkhateeb ${ }^{1}$, Marwa A. Amer ${ }^{1}$
} Forensic Medicine and Clinical Toxicology, Faculty of Medicine, Zagazig University, Egypt $^{1}$

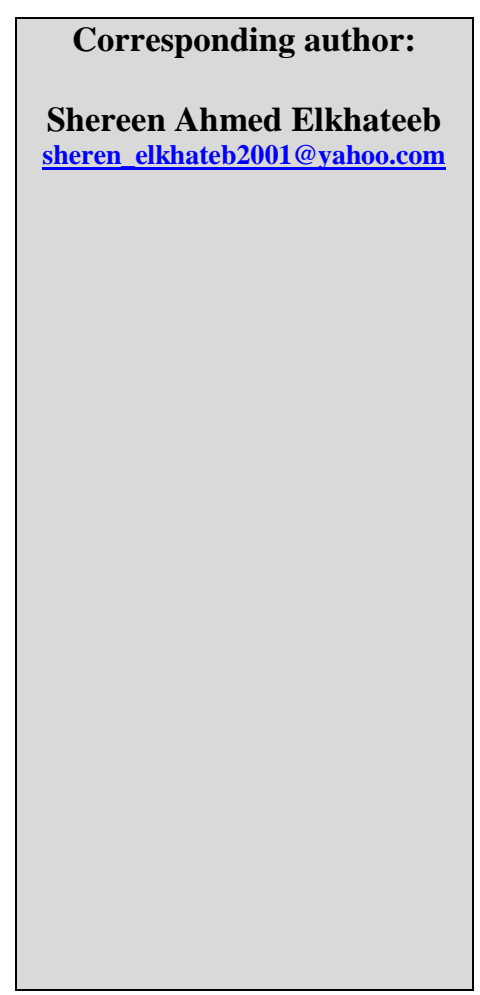

\begin{abstract}
In the last few months, COVID-19 pandemic caused some challenges for forensic practitioners. The crimes are still being committed and people still die due to causes not related to COVID-19, where the forensic practitioners is asked to clinically examine some cases and identify the cause and manner of death for others. Consequently, the forensic physicians will continue to examine victims of violence and the forensic pathologists should keep doing the autopsy of the corps of those killed by murder, suicide, accidentally or even sudden and unexpected death (like cases of heart attack or stroke). As any other individual in the community, these medico-legal cases may also be infected with COVID-19. SO, all forensic practitioners are at risk to catch COVID-19 infection either during examination of clinical cases that may be infected or during autopsy of infected bodies. The purpose of this review article is to know the potential risks facing forensic practitioners during examination of cases or doing autopsy in COVID-19 pandemic. It also indicates how to manage the dead bodies of suspected or confirmed cases of COVID-19 virus infection in order to minimize the risk of environmental contamination and the contagion of forensic practitioners and the proper guidelines and recommendations for the future.
\end{abstract}

Key wards: Forensic practitioners; clinical examination; death investigation; COVID-19 pandemic.

\section{INTRODUCTION}

Coronavirus disease 2019 (COVID-19), is a worldwide health issue (WHO, 2020). The most recently discovered coronavirus SARS$\mathrm{CoV}-2$ is considered belonging to hazard group 3 (HG3) category of infectious pathogens. HG3 is a significant group to deal with in clinical forensic medical practice and in forensic pathology practice (Osborn et al., 2020).

COVID-19 virus is highly infective. The incubation period is about two weeks, and continues for more than three weeks, in some cases (Backer et al., 2020; Liu et al., 2020). A significant number of viruses that reside in deceased persons infected with SARS-CoV-2, and the survival period of these viruses within the refrigerated corpses may be increased (Mao, et al., 2020).

COVID-19 outbreak has created certain challenges for forensic workers. Autopsy in the time of COVID-19 outbreak is considered a high risk autopsy. Risk of infection from corpses coming for autopsy for any purpose is unknown and hidden. These bodies may have no past medical records, or if present, contain inadequate information. Also, the cases may be asymptomatic. Beside, some of these deaths may have occurred in the hospital and there is a possibility of hospital acquired infections (Sapino et al., 2020). So, the objectives of this review article is to know the potential risks facing forensic practitioners during clinical 
examination of cases, during autopsy that may be either pathological, medico-legal or even academic and during sample collection in COVID-19 pandemic. Moreover, the safety precautions taken for protection during medical examination of cases, protection of the forensic staff in close proximity to dead bodies from contracting this infectious disease which may be accidently present and how virtual autopsy can help in this unprecedented time.

\section{THE POTENTIAL RISKS OF FORENSIC PRACTICE IN COVID-19 PANDEMIC TIME}

Forensic practitioners may examine patients, deceased bodies and tissues infected with SARS-CoV- 2 ((along with nonsymptomatic and suspect infections) (Mao et al., 2020).

\section{Potential risks during clinical forensic medical examination of cases}

The possibility to catch infection like COVID-19 during examination of individuals like prisoners, suspects and victims of crimes in clinical forensic medical practice may be present in this pandemic. Yu et al. (2020) displayed possible transmission among nonsymptomatic cases or among cases in the incubation period. Therefore forensic practitioners have to increase protection awareness at this critical time. Infection may be from patient to doctor or even from doctor to patient.

According to WHO scientific brief in March (2020), SARS-CoV- 2 is transmitted among people through respiratory droplets and touch routes. Transmission of droplets occurs when a person has respiratory symptoms (e.g., cough or sneeze) is in close contact with someone (within 1 m) that make this person at risk of exposure the mucosa of mouth, nose or conjunctiva to potentially infectious respiratory droplets. In the surrounding environment around the infected individual, transmission of droplets may occur via fomites. So, transmission of the SARS-CoV- 2 may occur through direct contact with infected persons and indirect contact with surfaces in the surrounding environment or with items used during infected person 's examination .

\section{Risks during investigation of the crime scene \\ Crime scenes should be processed} rapidly; crime scene investigators may not recognize the deceased health status, whether he (she) was travelled into pandemic area or contacting persons that may be infected. These suspicions indicate that the crime scene investigators are facing high risk of catching infection either during scene examination or sample collection from scene (Xue et al., 2020).

\section{Potential risks during autopsy}

COVID-19 virus can survive in an infected deceased body for a period of time after death, as it has strong survival and can resist cold environments. The corps of subjects who have died of COVID-19 could have huge amounts of the virus. Keeping cadavers in refrigerators can lengthen the virus' persistence within the body. In autopsy, forensic practitioners must do many procedures, where the virus can be passively released and the possibility of inhaling the virus is increased. In addition, sharp instrument injury and contact with body fluid spray can raise the risk of exposure during work (Mahallawi., 2018; Kampf, 2020; Joseph et al., 2020; Xue et al., 2020).

\section{Potential risks during samples collection, storage and transfer}

Forensic pathology investigation of certain organs need sample extraction, fixation, and sectioning after autopsy. Samples are then 
transferred to the pathology laboratory and stored in formalin for more than one week; any aerosols have the risk of effusion in air with subsequent endangering of physicians (Xue et al., 2020).

\section{BIOSAFETY RULES}

In the time of COVID-19 pandemic, each person or corpse is considered as potential source of infection because of the increasing level of contagion in communities as in hospitals and between the general population including asymptomatic cases. So, medico-legal examination of cases or autopsies should be accomplished with performing severe biosafety measures (Sapino et al., 2020).

Prior to any medico-legal examination of victims, crime scene investigation or deceased body dissection, forensic practitioners should perform full investigation to determine whether or not the person or the cause of death has a connection with COVID-19, in order to take suitable protection measurements such as wearing personal protective equipment, disinfection of instruments or using special designed autopsy rooms. Information from victims or relevant to deceased about "flu-like" symptoms, medical history, history of travel to an outbreak area or the history of contact with any potentially infected persons. Also, medical records should be requested from the hospital, family members, eyewitnesses, and mortuary workers (Xue et al., 2020).

It is recommended that, in cases of autopsies without apparent COVID-19 infection to do upper respiratory tract swabs on corpses if available. It is better to perform the swab within 2 hours of death to assess the absence or presence of COVID-19 infection to apply the safety rules (Fineschi et al., 2020). In cases of sudden unexpected death, if the upper respiratory tract swab is positive with previous history of flue like symptoms, the death may be certified without an autopsy. But if the test is negative, autopsy is needed to understand which natural disease was the cause of the decedent's symptoms.

Forensic practitioners should weight the risks and benefits related to any autopsy request. Autopsies and any post-mortem diagnostic maneuver should be carried out in special rooms that maintain proper safety conditions and forensic practitioners should wear protective overall, N95 mask, face shield and a double pair of autopsy gloves with cut-resistant glove in between. Any maneuver which may result in aerosols should be avoided. Organs and tissues samples for histopathological evaluations must be fixed immediately (Sapino et al., 2020). Xue et al. (2020) demonstrated that, autopsies in the time of pandemic should be performed in a superior designed autopsy rooms with three regions and two buffer sectors (clean region, first-level buffer sector, semi-contaminated region, second level buffer sector and contaminated region). Forensic practitioners have to dress the personal protective equipment in the clean region then consolidate autopsy instruments in the semi-contaminated region before ingoing the contaminated region for autopsy. Once finishing the dissection, the personal protective clothes should be disinfected first in the contaminated region then strongly disinfecting in the semi-contaminated region a second time prior to remove them. Everything must be directed for bio-safety clearance immediately. The contaminated region must contain a sufficient suction pressure, filtering settings for air release and sewage exoneration (Mao et al., 2020). Also, the samples sent for histopathological evaluations should be sealed well after sample extraction. The pathology laboratory should maintain standard negative pressure operating environments.

$\begin{array}{lcr}\text { IV. VIRTUAL } & \text { AUTOPSY AS A } \\ \text { SUBSTITUTION } & \text { TO } & \text { ORDINARY } \\ \text { AUTOPSY IN COVID-19 PANDEMIC }\end{array}$


In case of infectious diseases, virtopsy based on scanning and imaging technology will be a useful safe alternative to conventional autopsy. Performing computed tomography (CT) scan of the corpse prior to autopsy will help the forensic pathologists to expect the cause of death so, prevents them from directly contacting an infected or asymptomatic corpse. It is important to do a preliminary judgment on the deceased persons whether infected or not to take appropriate safety measures during subsequent autopsy such as doing upper respiratory tract swaps for suspected cases (Xue et al., 2020).

Combined CT and CT-angiography are considered as sensitive tools in diagnosing cause of death. Many studies investigated the sensitivity of postmortem imaging as postmortem CT (PMCT), PMCT angiography (PMCTA) and postmortem magnetic resonance imaging (PMMR) compared with ordinary autopsy in natural and traumatic death cases (Britt et al., 2016; Ampanozi et al., 2020). PMCTA is higher to autopsy plus CT without angiography in detecting medicolegally essential findings. The addition of the PMCTA increased the sensitivity of new major diagnoses from $71.4 \%$ in multiple detector CT (MDCT) only to $92.9 \%$ (Wichmann et al., 2012).

\section{RECOMMENDATIONS AND FUTURE PERSPECTIVES IN FORENSIC PRACTICE FOR SUCH PANDEMICS:}

- Upper respiratory tract swabs (nasopharyngeal swab or oropharyngeal swab) from suspected autopsy cases.

- In clinical forensic medical practice, thorough investigation of prisoners, suspects and victims of crimes, prior to examination is useful to determine whether or not the person has a relation with COVID-19. This is important to take suitable protective measures. Relevant facts from the person about medical history, travel history in an outbreak place or the contact history with any probably infected people. Measuring the person body temperature and if available rapid antibody test may be done before examination.

- Forensic practitioner like any health care worker should take oral chemoprophylaxis and wear personal protective equipment.

- Regular periodic follow up of forensic practitioners.

- Procedures for monitoring, managing and informing all relative visitors to hospitals, morgue and prisons.

- Conducting training courses for forensic practitioners on examination of cases, death investigations and occupational protection awareness for infectious diseases.

- Encouraging forensic pathologists to dissect infected cases especially with different criteria because, pathological autopsy results in each case will help clinicians to know more about the disease and understand its mechanisms well. These information will help physicians to put effective treatment protocols so, decrease morbidity and mortality rats.

- Autopsy rooms should be designed with high biosafety measures and it has to be provided with personal protective equipment to allow safe dealing with infected or suspected deceased persons. Special needs as certain suction system to prevent the reflux of contaminated aerosols and strong disinfection system. Beside, proper ventilation, good water supply, and sewage disposal.

- Virtopsy is considered a useful alternative to traditional autopsy in pandemics, as one of its advantages is to examine the corpse inside its bag and also, allow multiple experts from different countries to see the examination and share information in the same time through tele-forensics. So, forensic practitioners should increase their experience through continuous training courses on medico-legal radiology techniques and should be provided with 
equipment for virtopsy and high trained personnel in multiple morgues.

\section{REFERENCES}

1. Ampanozi, G., Halbheer, D., Ebert, L.C. et al. (2020): Postmortem imaging findings and cause of death determination compared with autopsy: a systematic review of diagnostic test accuracy and meta-analysis. Int $\mathbf{J}$ Legal Med; 134: 321-33.

https://doi.org/10.1007/s00414-019-

02140-y.

2. Backer, J.A., Klinkenberg, D. and Wallinga, J. (2020): Incubation period of 2019 novel coronavirus (2019-nCoV) infections among travellers from Wuhan, China, 20-28 January 2020. Euro Surveill. 2020. https:// doi.org/10.2807/1560-

7917.ES.2020.25.5.2000062.

3. Britt, M., Blokker, Ivo M., Wagensveld, Annick C., Weustink, J., Wolter Oosterhuis, M. G., Myriam Hunink (2016): Eur Radiol,; 26: 11591179. doi: 10.1007/s00330-015-3908-8.

4. Fineschi, V. et al. (2020): Management of the corpse with suspect, probable or confirmed COVID-19 respiratory infection - Italian interim recommendations for personnel potentially exposed to material from corpses, including body fluids, in morgue structures and during autopsy practice. Pathologica. https://doi.org/10.32074/ 1591-951X-1320.

5. Joseph, T.W., Kathy, L. and Gabriel, M.L. (2020): Now casting and forecasting the potential domestic and international spread of the 2019-nCoV outbreak originating in Wuhan, China: a modelling study. J. Lancet; 395: 689-
697. https:// doi.org/10.1016/s01406736(20)30260-9.

6. Kampf, G., Todt, D., Pfaender, S, et al. (2020): Persistence of coronaviruses on inanimate surfaces and their inactivation with biocidal agents. J. J Hosp Infect. 104; 246-25. https://doi.org/10.1016/j.jhin.2020.01.02 $\underline{2}$.

7. Liu, Z., Xing Bing, X. and Zhi, X. (2020): Expert Group on Novel Coronavirus Pneumonia Prevention and Control of China Preventive Medicine Association. [An update on the epidemiological characteristics of novel coronavirus pneumonia (COVID-19)]. Chinese;41:139-144.

8. Mahallawi, W.H. (2018): Case report: detection of the Middle East respiratory syndrome corona virus (MERS-CoV) in nasal secretions of a dead human. J. J Taibah Univ Med Sci; 13: 302-304. https://doi.org/10.1016/ j.jtumed.2017.07.004.

9. Mao, D.M., Zhou, N. and Zheng, D. (2020): Guide to the forensic pathology practice on death cases related to corona virus disease 2019 (COVID-19) (trial draft). Fa Yi Xue Za Zhi; 36:6-15. https://doi.org/10.12116/j.issn.10045619.2020.01.003.

10. Osborn, M., Lucas, S., Stewart, R., Swift, B. and Youd, E. (2020): Briefing on COVID-19 Autopsy practice relating to possible cases of COVID-19 (2019-nCov, novel coronavirus from China 2019/2020). The Royal Collage of Pathologists. February 2020 (online) last seen 12-6-2020.

11. Sapino, A., Facchetti, F., Bonoldi E., Gianatti, A. and Barbareschi, M. (2020): The autopsy debate during the COVID-19 emergency: the Italian experience on behalf of Società Italiana 
di Anatomia Patologica e Citologia SIAPEC Virchows Archi. https://doi.org/10.1007/s00428-02002828-2.

12. Wichmann, D., Obbelode, F., Vogel, H. et al. (2012): Virtual autopsy as an alternative to traditional medical autopsy in the intensive care unit; a prospective cohort study. Ann Intern Med 156:123130.

13. World Health Organization.

Coronavirus disease (COVID-19) outbreak. (2020): Available at: https://www.who.int/emergencies/ diseases/novel-coronavirus-2019.

14. World Health Organization scientific brief in March. Modes of transmission of virus causing COVID-19: implications for IPC precaution recommendations. https://reliefweb.int/report/world/modestransmission-virus-causing-covid-19implications-ipc-precautionrecommendations.

15. Xue, Y., Lai, L., Liu, C., Niu, Y., \& Zhao, J. (2020): Perspectives on the death investigation during the COVID19 pandemic. Forensic Science International (Online), 2, 126-128. https://doi.org/10.1016/j.fsisyn.2020.04. $\underline{001}$.

16. Yu, P., Zhu, J., Zhang, Z. et al. (2020): A familial cluster of infection associated with the 2019 novel coronavirus indicating potential person-to-person transmission during the incubation period. $J$ Infect Dis. doi:10.1093/infdis/jiaa077. 


\section{ممارسة الطب الثرعي في وقت جائحة كوفيد-9 1 : التحديات و آفاق المستقبل}

شيرين أحمد الخطيب1'، مروة عبدالمنعم عامر1

قسم الطب الثرعي و السموم إلاكلينيكية، كلية الطب البثرى، جامعة الزقازيق، مصر 1

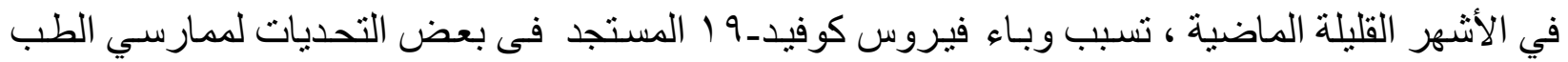

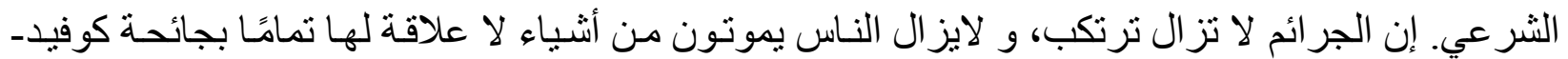

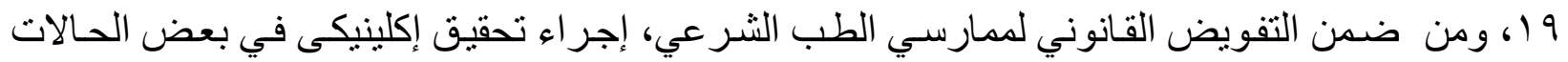

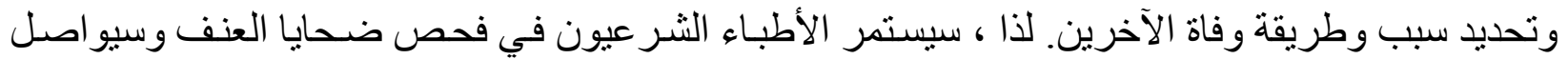

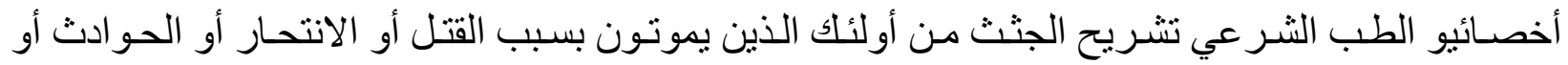

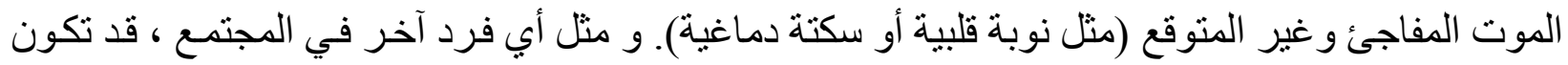

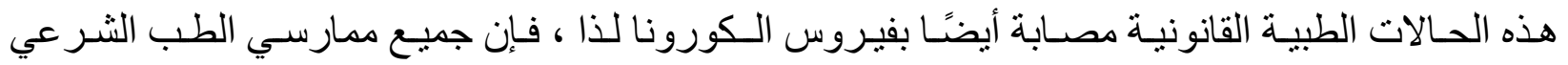

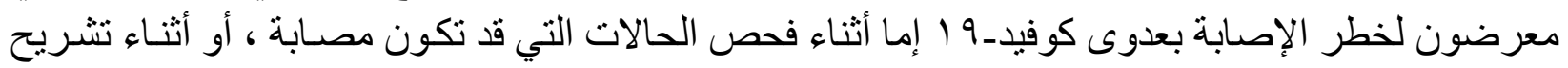

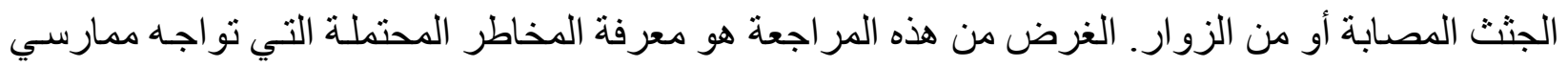

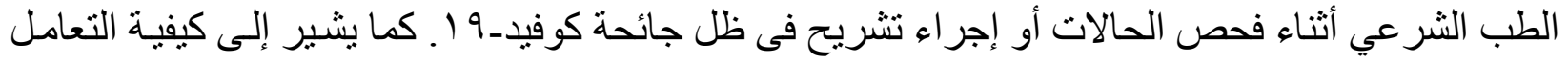

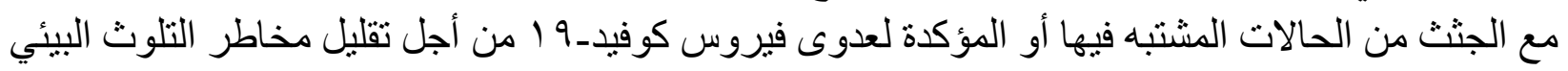

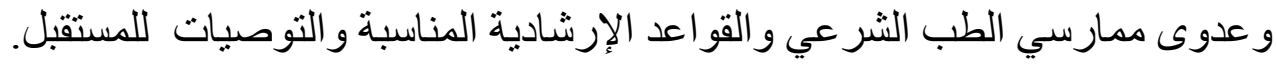

